\title{
Impact of intensive training on mental health, the experience of Port Said, Egypt
}

Saverio Bellizzi ${ }^{1 *} \mathbb{D}$, Amal Khalil$^{2}$, Ahmed Sawahel ${ }^{3}$, Alessandra Nivoli ${ }^{4}$, Liliana Lorettu ${ }^{4}$, Dina Sabry Said ${ }^{5}$ and Susanna Padrini ${ }^{6}$

\begin{abstract}
Background: Mental disorder is extremely common globally and integration of mental health in primary health services represents a critical gap especially in low- and middle-income Countries like Egypt. The World Health Organization has repeatedly called for effective training and support of primary care providers in the identification and treatment of mental health problems over the last decades.

Methods: This paper aimed to evaluate attitudes and knowledge of health care providers toward mentally ill patients and measure knowledge and retention of training messages over time. A 3-day mental health training workshop for nurses of public health facilities in the Governorate of Port Said was organized. Pre-training and post-training questionnaires (immediately after the workshop and 3 months later) were used. Significance of gain in scores was examined between baseline and following cross sectional rounds.

Results: The 73 participants in the study revealed a statistically significant improvement in knowledge and attitude toward mental health from the baseline (pre-training), from a general mean score for desirable answers of $10.5( \pm 1.2)$ to 21.2 ( \pm 0.6$)$. However, results slightly declined three months after from the workshop (18.5 $( \pm 0.6)$ ).

Conclusions: Intensive short-term training on mental illness could be instrumental in improving knowledge and attitudes in countries like Egypt with extensive needs in terms of quality of comprehensive healthcare at primary and secondary level. However, additional evidence is needed to improve retention of information over time and to translate knowledge into clinical practice.
\end{abstract}

\section{Introduction}

Mental disorder is extremely common in all countries, both in high-resourced and in low-resourced settings. While $14 \%$ of the global burden of disease is attributed to these disorders, most of the people affected, $75 \%$ in many low-income countries, do not have access to the treatment they need [1].

Impact of long-standing disability due to mental health conditions is huge and integration of mental health in primary health services represents a critical gap in

*Correspondence: saverio.bellizzi@gmail.com

${ }^{1}$ Independent Consultant, Geneva, Switzerland

Full list of author information is available at the end of the article several countries, especially low- and middle-income countries (LMICs) [2, 3].

Mental health services in Egypt are characterized by a substantial emphasis on hospitals with insufficient attention given to integrating mental health into primary care [4]. This leads to inadequate prevention, early detection as well as poor rehabilitation and social inclusion. One of the critical consequences is also represented by the lack of expertise on mental health issues across practitioners including family physicians, nurses and social workers [4].

The World Health Organization (WHO) has repeatedly called for effective training and support of primary care providers in the identification and treatment of mental health problems over the last several decades $[5,6]$.

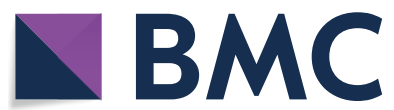

(c) The Author(s) 2021. This article is licensed under a Creative Commons Attribution 4.0 International License, which permits use, sharing, adaptation, distribution and reproduction in any medium or format, as long as you give appropriate credit to the original author(s) and the source, provide a link to the Creative Commons licence, and indicate if changes were made. The images or other third party material in this article are included in the article's Creative Commons licence, unless indicated otherwise in a credit line to the material. If material is not included in the article's Creative Commons licence and your intended use is not permitted by statutory regulation or exceeds the permitted use, you will need to obtain permission directly from the copyright holder. To view a copy of this licence, visit http://creativeco mmons.org/licenses/by/4.0/. The Creative Commons Public Domain Dedication waiver (http://creativecommons.org/publicdomain/ zero/1.0/) applies to the data made available in this article, unless otherwise stated in a credit line to the data. 
Mental health services face a number of challenges in Egypt, and a number of projects have sought to integrate mental health in the public health system [4]. The scale of training in medical schools and other training institutions does not reflect the importance of this field as contributor to morbidity. On the other hand, most resources are allocated to a few large centralized psychiatric hospitals, with inadequate availability of beds for acute inpatient care provision, especially due to the fact that around $60 \%$ of beds are occupied by long stay patients [7].

We organised a 3-day mental health training workshop for nurses of several primary and secondary level public health facilities, including the Psychiatric Hospital of Port Said, in the Governorate of Port Said, Egypt, in order to train them in core skills such as communication, assessment, mental state examination, diagnosis, and management of patients with mental illnesses. We also distributed questionnaires to the study-participants to pursue a three-fold objective of: (1) evaluating (pre-training) attitudes and knowledge of health care providers toward mentally ill patients; (2) to measure knowledge after the training; and (3) to explore the retention of training messages over time.

The main objective of this analysis was twofold. Specifically, we aimed to evaluate the baseline attitudes and knowledge of non-psychiatric nurses against those of psychiatric nurses at a different health facility as well as the retention of knowledge over time across the two categories of nurses.

\section{Methods}

Design

This is an observational analytical follow-up study. We organised a 3-day mental health training workshop for nurses of Public Health facilities in the Governorate of Port Said, in order to train them in core skills such as communication, assessment, mental state examination, diagnosis, and management of patients with mental illnesses.

In order to assess the retention of information provided during the training, the same questionnaire is distributed and administered (1) before the training, (2) immediately and (3) three months after the training.

\section{Sample}

This study was carried out amongst nurses, operating in public health facilities of the Port Said Governorate, who already participated in previous courses organized by the Italian Cooperation. While sample size calculation was not performed, we invited all the available nurses from the Port Said public health services in accordance with availability and working time. While all the 73 participants took the training, pre-test and first post-test in April 2018, only 49 (67.1\%) took the second test posttraining in September 2018 (Table 1).

\section{Training}

The training package was adapted using the modules for the training of primary care workers in low- and middleincome countries utilized in countries like Kenya and Iraq $[8,9]$. The package is highly structured into five overall units. The first focuses on core concepts (mental health and mental disorders, and their contribution to

Table 1 Distribution of nurses by health facility

\begin{tabular}{lccc}
\hline Health facility & $N(\%)$ & & Post-test \\
\cline { 2 - 4 } & Pre-test & & 3 months \\
\hline Primary Health Centers & $14(19.2)$ & $14(19.2)$ & $9(18.4)$ \\
Port Said Dental Hospital & $5(6.8)$ & $5(6.8)$ & $2(4.1)$ \\
El Ahrab Hospital & $2(3.1)$ & $2(3.1)$ & $2(4.1)$ \\
El Masah El Bahary Hospital & $3(4.1)$ & $3(4.1)$ & $3(6.2)$ \\
El Nasr Hospital & $4(5.1)$ & $4(5.1)$ & $3(6.2)$ \\
Port Said Epidemic Hospital & $3(4.1)$ & $3(4.1)$ & $3(6.2)$ \\
Port Said Geriatric Medical Centre & $3(4.1)$ & $3(4.1)$ & $3(6.2)$ \\
Port Said Ophthalmology Hospital & $7(9.6)$ & $7(9.6)$ & $2(4.1)$ \\
Port Fouad General Hospital & $9(12.3)$ & $9(12.3)$ & $5(10.2)$ \\
Port Said General Hospital & $6(8.2)$ & $6(8.2)$ & $6(12.1)$ \\
Port Said Psychiatric Hospital & $11(15.1)$ & $11(15.1)$ & $7(14.0)$ \\
Zohour Hospital & $5(6.8)$ & $5(6.8)$ & $3(6.2)$ \\
Port Said Obstetric Hospital & $1(1.5)$ & $1(1.5)$ & $1(2.0)$ \\
\hline
\end{tabular}


physical health, economic and social outcomes). The second addresses core skills such as communication, assessment, mental state examination, diagnosis, management, managing difficult cases, management of violence and breaking bad news. The third covers common neurological disorders such as epilepsy and dementia while the fourth focuses on psychiatric disorders following the World Health Organization primary care guidelines. Finally, the fifth deals with policy and legislation around integration of mental health into annual operational plans. Other common severe disorders were discussed, including schizophrenia and bipolar disorder [10].

Each unit was subdivided into a series of 30-min modules delivered by trained Psychiatrists. The course was administered over 3 days and consisted of a combination of lectures, case studies and problem-solving scenarios, and took place in the month of April 2018.

\section{Questionnaire}

Each participant was invited to fill a questionnaire, based on previous studies $[2,11]$, including several aspects of the syllabus of the training (Table 2). Specifically, the questionnaire consists of 25 statements and for each item the respondent is required to state whether he agrees or disagrees. The questionnaire was pre-tested and validated among a small sample of nurses of the Port Said Nursing Institute.

The workshop was conducted in the Port Said Nurses Institute and was supported by the Egypt Ministry of Health and by the Italian Cooperation.

\section{Data collection and statistical analysis}

Data were entered by a medical epidemiologist in Excel files, which were uploaded for analysis using the software Stata/MP v.14.

Desirable responses for each item in the questionnaire (Table 1 ) was given a score of 1 while undesirable responses will be given a score of 0 . Score before and after training, as well as after 3 months was calculated. Significance of gain in scores was examined between baseline and following cross sectional rounds using Paired T-Student test.

Table 2 Questionnaire

\begin{tabular}{|c|c|c|}
\hline Item & Desirable answer & Code answer \\
\hline 1. Health is absence of illnesses & Disagree & 1 \\
\hline 2. Depression is a form of disability & Agree & 1 \\
\hline 3. Criteria of Schizophrenia include double or multi-personality & Disagree & 1 \\
\hline 4. Psychiatric patients are usually aggressive and represent a danger for himself and for others & Disagree & 1 \\
\hline 5. Psychiatric medication cause addiction & Disagree & 1 \\
\hline 6. Delusion is the hallucination of schizophrenia patients & Disagree & 1 \\
\hline 7. Headache, stomachache, fatigue, muscle pain are symptoms of depression & Agree & 1 \\
\hline 8. Psychiatric nurses are always subject to verbal or physical aggression during care for psychiatric patient & Disagree & 1 \\
\hline 9. To improve depressed patient status, advice to be more religious, to pray, and to appreciate positive sides of life & Disagree & 1 \\
\hline $\begin{array}{l}\text { 10. Stop working, lack of concentration, and insomnia, and being sarcastic towards other people, and non-flexibility } \\
\text { on others' opinion, are some of the criteria for maniac episodes }\end{array}$ & Agree & 1 \\
\hline 11. Electro-convulsive therapy (ECT) is not a safe treatment for mental ill patients & Disagree & 1 \\
\hline $\begin{array}{l}\text { 12. Before diagnosing a psychiatric patient we need to exclude the following: HIV, Hypothyroidism, DM, cerebral } \\
\text { palsy }\end{array}$ & Agree & 1 \\
\hline 13. No need to measure vital sign for psychiatric patient unless he is diagnoses with a physical disease & Disagree & 1 \\
\hline 14. Reading Quran and prayer will cure psychiatric illness & Disagree & 1 \\
\hline 15. Nurses could support and help depressive patient by reporting stories of other patients in worse conditions & Disagree & 1 \\
\hline 16. Psychiatric nurse assessment includes physical appearance, social status, stuttering, and lab investigation & Agree & 1 \\
\hline 17. Psychiatric hospital is the best place to treat psychiatric patients & Disagree & 1 \\
\hline 18. Psychiatric patient needs special care that is not available in general hospital & Disagree & 1 \\
\hline 19. Neglect answering question is the best way to deal with anxious patient & Disagree & 1 \\
\hline 20. Most of psychiatric diseases are because of lack of faith and not being religious & Disagree & 1 \\
\hline 21. Religious clergy are the best ones to treat obsessive compulsive patients (OCD) & Disagree & 1 \\
\hline 22. Schizophrenia percentage increases in lower income society more than high income society & Disagree & 1 \\
\hline 23. We should not ask depressed patient about suicidal thoughts so he will not commit it & Disagree & 1 \\
\hline 24. Family and social support are very important to support psychiatric patients & Agree & 1 \\
\hline 25. Psychiatric diseases are considered chronic diseases like DM and hypertension & Agree & 1 \\
\hline
\end{tabular}




\section{Results}

\section{Pre-training test}

The general mean score for desirable answers per participant was $10.5( \pm 1.2)$ and ranged from a minimum of 3 up to a maximum value of 18 (consider that the maximum score would have been 25). The mean score for desirable answers in NON psychiatric nurses was 9.4 $( \pm 1.4)$ and ranged from a minimum of 3 up to a maximum value of 18 . The mean score for desirable answers in psychiatric nurses was $13.9( \pm 1.0)$ and ranged from a minimum of 9 up to a maximum value of 18 . The most problematic items were the no. 3 (criteria of Schizophrenia include double or multi-personality), the no. 6 (delusion is the hallucination of schizophrenia patients), the no. 8 (psychiatric nurses are always subject to verbal or physical aggression during care for psychiatric patient), and the no. 18 (psychiatric patient need special care that is not available in an general hospital), which respectively totalled 4, 6, 3, and 6 correct answers. The least problematic items were the no. 7 (headache, stomach ache, fatigue, muscle pain are symptoms of depression), and the no. 24 (family and social support are very important to support psychiatric patients), which totalled 39 and 43 corrects answers.

\section{Post-training tests}

As shown in Table 3, knowledge around mental health significantly increased when comparing the overall score for each of the 25 items included in the questionnaire before and immediately after the 3-day training. Item no. 19 ("Neglect answering question is the best way to deal with anxious patient") is the only subject that did not register a statistically significant increase in knowledge $(\mathrm{p}=0.06)$.

On the other hand, the questionnaire administered after three months showed a significant decline in knowledge for six items: "depression is a form of disability", "delusion is the hallucination of schizophrenia patients", "headache, stomach ache, fatigue, muscle pain are symptoms of depression", "psychiatric hospital is the best place to treat psychiatric patients", "we should not ask depressed patient about suicidal thoughts so he will not commit it", and "psychiatric diseases are considered chronic diseases like DM and hypertension" (Table 3).

Table 3 Differences in participants' attitudes to mental health issues before and after training

\begin{tabular}{|c|c|c|c|c|c|}
\hline $\begin{array}{l}\text { Total desirable answers } \\
\text { achieved }\end{array}$ & $\begin{array}{l}\text { Pre-test (73 } \\
\text { participants) }\end{array}$ & $\begin{array}{l}\text { Post-test (73 } \\
\text { participants) }\end{array}$ & P-value (Pre vs. Post) & $\begin{array}{l}\text { Post-test after three months ( } 49 \\
\text { participants) }\end{array}$ & $\begin{array}{l}\text { P-value (Post } \\
\text { vs. } 3 \text { months) }\end{array}$ \\
\hline Item 1 & 24 & 68 & $<0.05$ & 39 & 0.04 \\
\hline Item 2 & 25 & 51 & $<0.05$ & 21 & $<0.05$ \\
\hline Item 3 & 12 & 58 & $<0.05$ & 30 & 0.03 \\
\hline Item 4 & 26 & 50 & $<0.05$ & 32 & 0.7 \\
\hline Item 5 & 32 & 63 & $<0.05$ & 41 & 0.8 \\
\hline Item 6 & 22 & 61 & $<0.05$ & 30 & $<0.05$ \\
\hline Item 7 & 62 & 70 & 0.04 & 34 & $<0.05$ \\
\hline Item 8 & 10 & 32 & $<0.05$ & 19 & 0.07 \\
\hline Item 9 & 19 & 64 & $<0.05$ & 41 & 0.8 \\
\hline Item 10 & 50 & 69 & 0.03 & 44 & 0.09 \\
\hline Item 11 & 34 & 72 & $<0.05$ & 43 & 0.06 \\
\hline Item 12 & 41 & 50 & 0.04 & 26 & 0.03 \\
\hline Item 13 & 57 & 71 & 0.02 & 43 & 0.04 \\
\hline Item 14 & 20 & 67 & $<0.05$ & 45 & 0.9 \\
\hline Item 15 & 27 & 68 & $<0.05$ & 36 & 0.03 \\
\hline Item 16 & 52 & 67 & 0.03 & 41 & 0.05 \\
\hline Item 17 & 21 & 63 & $<0.05$ & 32 & $<0.05$ \\
\hline Item 18 & 12 & 36 & $<0.05$ & 28 & 0.07 \\
\hline Item 19 & 50 & 63 & 0.06 & 45 & 0.4 \\
\hline Item 20 & 33 & 70 & $<0.05$ & 44 & 0.9 \\
\hline Item 21 & 48 & 70 & $<0.05$ & 46 & 0.8 \\
\hline Item 22 & 49 & 66 & 0.05 & 40 & 0.1 \\
\hline Item 23 & 18 & 58 & $<0.05$ & 29 & $<0.05$ \\
\hline Item 24 & 67 & 68 & 0.4 & 43 & 0.3 \\
\hline Item 25 & 32 & 70 & $<0.05$ & 31 & $<0.05$ \\
\hline
\end{tabular}


The first post-training test general mean score for desirable answers per participant was $21.2( \pm 0.6)$ and ranged from a minimum of 14 up to a maximum value of 24. The mean score for desirable answers in NON psychiatric nurses was $20.0( \pm 0.7)$ and ranged from a minimum of 14 up to a maximum value of 24 . The mean score for desirable answers in psychiatric nurses was 21.8 $( \pm 0.3)$ and ranged from a minimum of 16 up to a maximum value of 22 . More than 20 participants replied correctly for all items except for no. 8 (psychiatric nurses are always subject to verbal or physical aggression during care for psychiatric patient) for which only 10 nurses answered correctly, and the no. 18 (psychiatric patient need special care that is not available in general hospital) for which only $16 \mathrm{did}$. Almost all participants correctly answered to item no. 1 (health is absence of illnesses), no. 7 (headache, stomach ache, fatigue, muscle pain are symptoms of depression), no. 10 (stop working, lack of concentration, and insomnia, and being sarcastic towards other people, and non-flexibility on others' opinion, are some of the criteria for maniac), no. 11 [electro-convulsive therapy (ECT) is not a safe treatment for mental ill patients], no. 13 (no need to measure vital sign for psychiatric patient unless he is diagnoses with a physical disease), no. 20 (most of psychiatric diseases are because of lack of faith and not being religious), and no. 25 (psychiatric diseases are considered chronic diseases like DM and hypertension).

The second post-training test general mean score for desirable answers was $18.5( \pm 0.7)$ and a similar decline was noted for both groups, psychiatric nurses and NON psychiatric nurses, which recorded respectively 18.9 $( \pm 0.6)$ and $18.1( \pm 0.6)$.

\section{Discussion}

This study showed the potential value of training nurses of different departments and operating at both primary and secondary health level. The statistically significant improvement in acquisition of knowledge and positive attitudes towards mental disorders is a fundamental finding of this study. Such a combination (knowledge and attitudes) is indeed is critical for quality and efficient service delivery.

Similar results were indicated by previous reports that examined changes in knowledge and attitude of primary healthcare workers and primary care physicians after short-term trainings [10, 12-14].

A WHO collaborative study also showed an equal magnitude increase in knowledge and behavior of general health workers in six different low- and middle-income countries despite approaches to training varied between study areas [15]. The same study emphasized the persistence of knowledge and attitude for 18 months post training, which is in line with our study in spite of a slight decline.

As correctly inferred by Ignacio et al., some culturally ingrained beliefs are reflected in specific negative attitudes and may require longer term interventions to reverse them [15]. In the case of our experience in Port Said, this is particularly true for the items "psychiatric nurses are always subject to verbal or physical aggression during care for psychiatric patient", and "psychiatric patient need special care that is not available in general hospital", for both of which the correct answer is No.

While a general improvement in knowledge was registered, is also important to remark how no significant changes were detected for some items, which remained similar to the baseline scores. This was showed also by Chinnayya et al. [11] and reinforces the theory of culturally ingrained beliefs and attitudes, which might require alternative and longer strategies of training.

It is essential to embed mental health knowledge and skills within primary and secondary care and the integration of mental health into the basic training of staff would be fundamental in association with post basic training and continuing professional development and for building independent mental health researchers [16].

As very well-emphasized by Makanjuola et al. [2] there is "no health without mental health" and overall service delivery would drastically benefit from the inclusion of mental health knowledge and positive attitudes. In fact, essential universal health would be an unattainable goal if the complex relationship between physical and mental health is not addressed at the healthcare service delivery portal level [17-19].

While the protocol for our study was substantiated by a literature review and each step was carefully implemented, a few limitations are present.

First of all, this study did not explore whether the skills acquired would impact on clinical practice. However, some studies have reported significant improved skill changes in workplaces after intensive training with similar approaches [13]. Secondly, although questionnaires were anonymous and completely confidential, changes were obtained by self-report and may have been influenced by response bias rather than reflecting a "true conviction". Finally, despite a telephone attempt to track those who did not complete the second post-training, none undertook the questionnaire on another possible date, thus representing a potential source of knowledge bias.

To conclude, intensive short-term training on mental illness could be instrumental in improving knowledge and attitudes in countries like Egypt with extensive needs in terms of quality of comprehensive healthcare at primary and secondary level. However, retention of 
information seems to decline overtime. Further studies are warranted that are tailored to local contexts in order to investigate how such programs translate into clinical practice.

\section{Acknowledgements}

We thank Professor Piero Capuccinelli at the University of Sassari for his valuable comments and suggestions. We also thank Dr. Federico Chiodi Daelli of AISPO for the logistic support to conduct our study.

\section{Authors' contributions}

SB and SP conceived the idea of the project; $A K$ and AS conducted the training; SB, AN and LL collected and analyzed data; SB, AN, LL, DSS and AS interpreted data; SB and SP wrote the first draft of the manuscript. All authors read and approved the final manuscript.

\section{Funding}

No funding used for this report.

\section{Availability of data and materials}

Data are available under request.

\section{Declarations}

\section{Ethics approval and consent to participate}

This study was conducted in accordance with the agreement between the Ministry of Health of Egypt, the Health Directorate of Port Said and the Italian NGO AISPO, which operates under the umbrella of the Italian Cooperation in Egypt in the Port Said Training Institute. Questionnaires were completely anonymous and all participants gave consent to use data for this report.

\section{Consent for publication}

Not applicable.

\section{Competing interests}

The authors declare that they have no competing interests.

\section{Author details}

${ }^{1}$ Independent Consultant, Geneva, Switzerland. ${ }^{2}$ Nursing Faculty, Port Said, Egypt. ${ }^{3}$ Helwan Mental Health Hospital, Cairo, Egypt. ${ }^{4}$ University of Sassari, Sassari, Italy. ${ }^{5}$ College of Business Administration, American University of the Middle East, Eqaila, Kuwait. ${ }^{6}$ A.I.S.P.O. Associazione Italiana per la Solidarietà tra i Popoli, Milan, Italy.

Received: 24 September 2020 Accepted: 29 November 2020 Published online: 15 April 2021

\section{References}

1. World Health Organization. WHO Mental Health Gap Action Programme (mhGAP). Geneva: World Health Organization; 2017. https://www. who.int/publications/i/item/mhgap-intervention-guide---version-2.0. Accessed 15 Aug 2020.
2. Makanjuola V, Doku V, Jenkins R, Gureje O. Impact of a one-week intensive 'training of trainers' workshop for community health workers in south-west Nigeria. Ment Health Fam Med. 2012;9(1):33-8.

3. Okasha A. Mental health services in the Arab world. East Mediterr Health J. 1999;5(2):223-30. Erratum in: East Mediterr Health J 2000;5(5):1059.

4. Jenkins R, Heshmat A, Loza N, et al. Mental health policy and development in Egypt - integrating mental health into health sector reforms 2001-9. Int J Ment Health Syst. 2010;4:17.

5. Prince M, Patel V, Saxena S, Maj M, Maselko J, Phillips MR, Rahman A. No health without mental health. Lancet. 2007;370(9590):859-77.

6. Lancet Global Mental Health Group. Scale-up services for mental disorders: a call for action. Lancet. 2007:370(9594):1241-52.

7. Egypt Mental Health. Regional Office for the Eastern Mediterranean. World Health Organization. http://www.emro.who.int/egy/programmes/ mental-health.html. Accessed 15 Aug 2020.

8. Jenkins R, Kiima D, Okonji M, et al. Integration of mental health into primary care and community health working in Kenya: context, rationale, coverage and sustainability. Ment Health Fam Med. 2010;7(1):37-47.

9. Sadik S, Abdulrahman S, Bradley M, Jenkins R. Integrating mental health into primary health care in Iraq. Ment Health Fam Med. 2011:8(1):39-49.

10. Jenkins R, Kiima D, Njenga F, et al. Integration of mental health into primary care in Kenya. World Psychiatry. 2010;9:118-20.

11. Chinnayya HP, Chandrashekar CR, Moily S, et al. Training primary care health workers in mental health care: evaluation of attitudes towards mental illness before and after training. Int J Soc Psychiatry. 1990;36(4):300-7.

12. Ahrens J, Kokota D, Mafuta C, et al. Implementing an mhGAP-based training and supervision package to improve healthcare workers' competencies and access to mental health care in Malawi. Int J Ment Health Syst. 2020;14:11.

13. Sadiq S, Abdul Rahman S, Bradley M. Integrating mental health into primary care in Iraq. Ment Health Fam Med. 2011;8:39-49.

14. Mansouri N, Gharaee B, Shariat SV, et al. The change in attitude and knowledge of health care personnel and general population following trainings provided during integration of mental health in primary health care in Iran: a systematic review. Int J Ment Health Syst. 2009;3(1):15.

15. Ignacio L, De Arango MV, Baltazar J. Knowledge and attitudes of primary health care personnel concerning mental health problems in developing countries: a follow-up study. Int J Epidemiol. 1989;18:669-73.

16. Tichenor M. Essential universal health coverage needs local capacity development. Lancet Glob Health. 2020;8(6):e748-9.

17. Fawzy ME. Quality of life and human rights conditions in a public psychiatric hospital in Cairo. Int J Hum Rights Healthc. 2015;8(4):199-217.

18. Esmayel EM, Eldarawy MM, Hassan MM, et al. Mental health problems and sociodemographic correlates in elderly medical inpatients in a University Hospital in Egypt. Curr Gerontol Geriatr Res. 2013. https://doi.org/ 10.1155/2013/923710.

19. Malavia T, Nimgaonkar V, Bhatia T, et al. Outcomes from Indo-United States-Egypt tri-national psychiatric research training programmes. Health Res Policy Syst. 2020;18:82.

\section{Publisher's note}

Springer Nature remains neutral with regard to jurisdictional claims in published maps and institutional affiliations. 